\title{
Correlations between central corneal power, axial length, anterior chamber depth and central corneal thickness of near-emmetropic young university students in Palestine
}

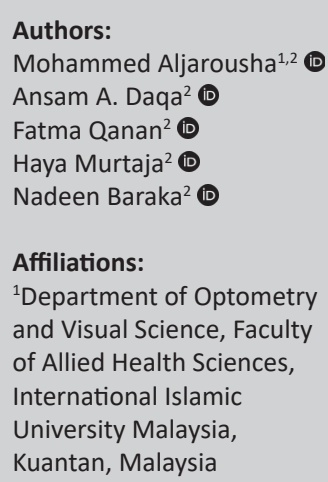

Background: Researchers have found that the refractive states of the eye are influenced by a variety of variables.

Aim: This study investigated the correlation between the central corneal power (CCP) and a number of variables, which include axial length (AL), anterior chamber depth (ACD) and the central corneal thickness (CCT) in near-emmetropic eyes of students.

Setting: The study was conducted in the Optometry Laboratory of the Islamic University-Gaza (IUG), Palestine.

Methods: In a prospective analysis, 200 near-emmetropic students were examined from February 2019 to May 2019 with an ultrasound scanner (A-scan), ultrasonic pachymeter and Visionix L79 automated refractometer Keratometer (ARK). Only the data of one eye were randomly chosen for investigation.

Results: The means and standard deviations (s.d.) of the CCP, AL, ACD and CCT for male students $(n=97)$ were 43.19 dioptre (D) $\pm 1.34 \mathrm{D}, 23.54 \mathrm{~mm} \pm 0.68 \mathrm{~mm}, 3.59 \mathrm{~mm} \pm 0.26 \mathrm{~mm}$ and $549 \mu \mathrm{m} \pm 33 \mu \mathrm{m}$, respectively. Furthermore, the means \pm s.d. of 103 female students were as follows: CCP $43.85 \mathrm{D} \pm 1.43 \mathrm{D}, \mathrm{AL} 22.94 \mathrm{~mm} \pm 0.69 \mathrm{~mm}, \mathrm{ACD} 3.35 \mathrm{~mm} \pm 0.25 \mathrm{~mm}$ and CCT $543 \mu \mathrm{m} \pm 35 \mu \mathrm{m}$. There was a significant association between CCP and gender $(p=0.00)$. There was a negative significant correlation between CCP and AL for both the male $(r=-0.64$; $p=0.00)$ and the female $(r=-0.71, p=0.00)$ participants.

Conclusion: This study provided information on CCP, AL, ACD and CCT in near-emmetropic eyes of adults. In male students, CCP was flatter and AL was longer when compared with female Palestinian students.

Keywords: central corneal power; axial length; anterior chamber depth; ultrasonic pachymeter, automated refractometer-keratometer; corneal topography; Islamic University-Gaza; central corneal thickness.

\section{Introduction}

Cowan defines emmetropia as 'a state of refraction in which parallel rays of light are brought to focus on the retina when the eye is at the resting state' ${ }^{1}$ Emmetropia is considered to be a feature of the normal eye. ${ }^{2}$ Researchers have found that refractive state of the eye is influenced by a variety of variables, including central corneal power (CCP), axial length(AL), anterior chamber depth (ACD) and central corneal thickness (CCT) ${ }^{3,4,5}$ Previous studies indicated prevalence rates of near-emmetropia subjects in the following countries: Saudi Arabia (54.1\%), Nigeria (71.5\%), Germany (37\%), Brazil (15.9\%) and Pakistan $(36.7 \%) \cdot{ }^{6,7,8,9,10}$

Researchers have shown that CCP is a vital indicator of corneal status, which forms two-thirds of the focusing power of the eye. ${ }^{11,12}$ The same group of researchers defined AL as the distance from the anterior corneal surface to the retinal pigment epithelium or Bruch's membrane, and AL is usually measured in millimetres. There were previous reports that ACD is vital and used in newer, theoretical biometric formulas for intraocular lens (IOLs) power calculations and for the implantation of Phakic IOLs, ${ }^{13}$ and the internal depth of the anterior chamber (AC) is approximately 3.17 millimetres (mm). ${ }^{8}$ According to Doughty and Jonuscheit, ${ }^{14}$ and Ashwin et al., ${ }^{15}$ CCT is an 
indicator of corneal health status and influences applanation tonometry, with decisions for refractive surgery dependent on sufficient CCT.

It is important for practitioners to determine normal values for ocular parameters in near-emmetropic students in order to initiate proper management and assessment of patients. To evaluate the ocular component values of near-emmetropic students, we performed a prospective analysis by A-Scan Ultrasound Biometry, pachymetry, autorefraction and keratometry. The results of this investigation may enhance the understanding of the relationship between CCP, AL, ACD and CCT in normal Palestinian young adult eyes.

\section{Materials and methods}

A prospective study was carried out using a convenience sampling method based on the assessment of nearemmetropic students who were attending the Optometry Laboratory of the Islamic University of Gaza (IUG), Palestine. Only the data of one eye were randomly chosen for investigation. The study protocol received approval from the local Ethics Committee. In this study, 200 young students were examined from February 2019 to May 2019. The appropriate sample size was determined based on OpenEpi software (Sullivan, Atlanta, GA, United States [US]). ${ }^{16}$

The age group of students in this study was 18-23 years, with a spherical equivalent (SE) refractive error (RE) of less than \pm 0.50 dioptre (D). The clinical examinations included CCP, $\mathrm{AL}, \mathrm{ACD}$ and CCT measurements, which were measured using an ultrasonic pachymeter (Sonomed PacScan 300 AP and Combination A-Scan Pachymeter) with topical anaesthesia ( $0.1 \% \mathrm{Hcl}$ Localin). The technique was measured at the apical corneal position by adjusting the tip of probe with minimal corneal compression. Three consecutive readings were recorded per eye, and then the averages were used in the current research. We measured the CCP using the Visionix L79 Automated Refractometer Keratometer (ARK)Topography instrument (Visionix Ltd, Chartres, France). Values of the CCP were obtained prospectively in this research. In this study, all students had uncompensated visual acuities (VAs) between 6/6 and 6/7.5. Individuals with previous ocular surgeries or laser treatment, contact lens wear and those taking any form of medications, such as antihistamines, diuretics and drugs used to treat high blood pressure, were excluded from the study.

Data analysis was conducted using the Statistical Package for Social Sciences (IBM SPSS, version 20, SPSS Inc., Chicago, IL, US). Scores were reported as means and standard deviations (s.d.) in near-emmetropic students, with statistical significance accepted at $p<0.05$. In this study, the distribution of CCP was investigated with a histogram (see Figure 1). Independent sample $t$-tests were applied to compare CCP values between male and female groups, and one-way analysis of variance (ANOVA) was used to compare
CCP scores between the age groups. In addition, Pearson's correlation coefficients were used to evaluate the correlations between $\mathrm{CCP}$ and other variables. The dependent factors included AL, ACD and CCT.

\section{Ethical considerations}

This article followed all necessary ethical standards for research with direct contact with human subjects.

\section{Results}

A total of 200 students aged 18-23 years were examined in the Optometry Laboratory of the IUG, Palestine. The means and s.d. of the CCP, AL, ACD and CCT for the near-emmetropic male students $(n=97)$ were $43.19 \mathrm{D} \pm$ $1.34 \mathrm{D}, 23.54 \mathrm{~mm} \pm 0.68 \mathrm{~mm}, 3.59 \mathrm{~mm} \pm 0.26 \mathrm{~mm}$ and $549 \mu \mathrm{m} \pm 33 \mu \mathrm{m}$, respectively. In addition, the means \pm s.d. for 103 near-emmetropic female participants were as follows: CCP $43.85 \mathrm{D} \pm 1.43 \mathrm{D}, \mathrm{AL} 22.94 \mathrm{~mm} \pm 0.69 \mathrm{~mm}$, ACD $3.35 \mathrm{~mm} \pm 0.25 \mathrm{~mm}$ and CCT 543 micrometres $(\mu \mathrm{m}) \pm$ $35 \mu \mathrm{m}$ (Table 1). Based on the findings of the normality test, CCP scores were normally distributed, as presented in Figure 1.

Mean CCP scores by gender and age are shown in Tables 2 and 3 . There was a significant association between CCP and gender $(p=0.00)$. However, there was no significant difference in CCP values between the age groups $(p=0.49)$.

There were negative significant correlations between CCP and AL for both the men $(r=-0.64 ; p=0.00)$ and women $(r=-0.71, p=0.00$; Figures 2 and 3$)$. The correlations were 0.15 and 0.08 between CCP and ACD for the male and female students, respectively (Table 4). Additionally, no significant correlation was found between CCP and CCT for male and female eyes ( $p=0.16$ and $p=0.86$, respectively).

\section{Discussion}

To our knowledge, this is the first prospective analysis on the normal young adult CCP in Gaza Strip, Palestine. The results of the current study showed that the mean \pm s.d. values for CCP were $43.19 \mathrm{D} \pm 1.34 \mathrm{D}$ for men and $43.85 \mathrm{D} \pm 1.43 \mathrm{D}$ for women. All students were nearemmetropic and healthy volunteers. These findings are comparable with that of Mallen et al. ${ }^{17}$ who determined

TABLE 1: Characteristics for 200 students (97 males and 103 females), aged 18-23 years.

\begin{tabular}{lcccc}
\hline Variable & CCP $(D)$ & AL $(\mathrm{mm})$ & ACD $(\mathrm{mm})$ & CCT $(\mu \mathrm{m})$ \\
\hline Males & & & & \\
Mean \pm s.d. & $43.19 \pm 1.34$ & $23.54 \pm 0.68$ & $3.59 \pm 0.26$ & $549 \pm 33$ \\
Range & $48.25-40.25$ & $20.66-24.96$ & $2.80-4.31$ & $475-644$ \\
Females & & & & \\
Mean \pm s.d. & $43.85 \pm 1.43$ & $22.94 \pm 0.69$ & $3.35 \pm 0.25$ & $543 \pm 35$ \\
Range & $47.25-40.00$ & $21.11-24.86$ & $2.72-4.09$ & $427-625$ \\
\hline
\end{tabular}

s.d., standard deviation; $C C P$, central corneal power; $A L$, axial length; $A C D$, anterior chamber depth; CCT, central corneal thickness; $\mathrm{mm}$, millimetres; $\mathrm{D}$, dioptre; $\mu \mathrm{m}$, micrometres. 


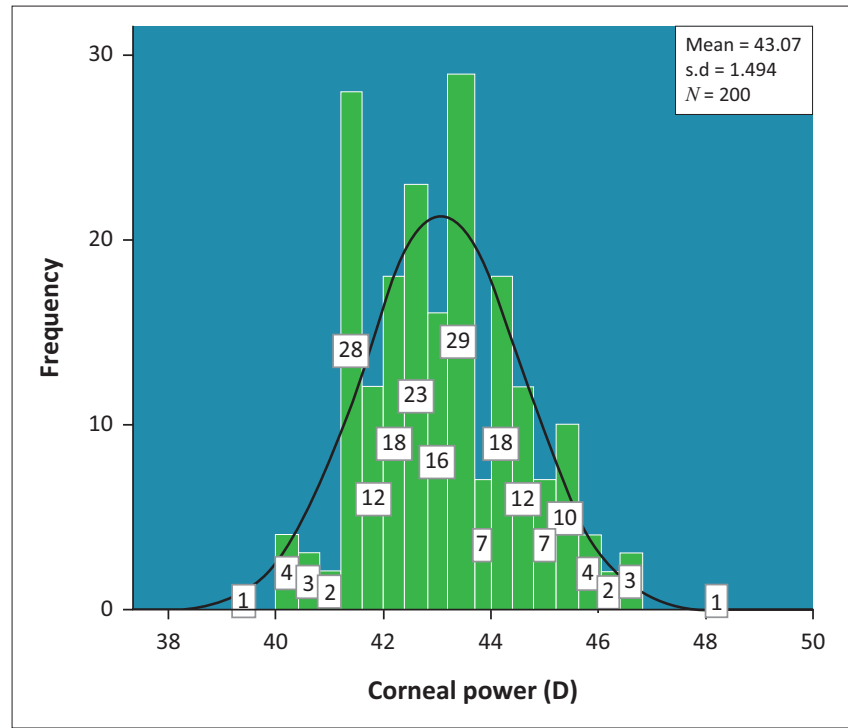

D, dioptre; s.d., standard deviation.

FIGURE 1: Histogram presenting the distribution of central corneal power of near-emmetropic (97 men and 103 women) students, aged 18-23 years.

TABLE 2: Distribution of central corneal power (CCP) in near-emmetropic students (97 men and 103 women).

\begin{tabular}{lcc}
\hline Ages (years) & $\begin{array}{c}\text { Males } \\
\mathbf{C C P}^{\dagger}, \mathbf{C P}^{\dagger} \text { (mean } \pm \text { s.d.) }\end{array}$ & $\begin{array}{c}\text { Females } \\
\mathbf{C C P}^{\dagger}, \mathbf{C P}^{\dagger} \text { (mean } \pm \text { s.d.) }\end{array}$ \\
\hline 18 & $43.35 \pm 1.55 \mathrm{D}$ & $43.94 \pm 1.63 \mathrm{D}$ \\
19 & $42.84 \pm 1.21 \mathrm{D}$ & $43.34 \pm 1.50 \mathrm{D}$ \\
20 & $42.82 \pm 1.56 \mathrm{D}$ & $43.64 \pm 1.53 \mathrm{D}$ \\
21 & $42.45 \pm 0.99 \mathrm{D}$ & $43.10 \pm 1.30 \mathrm{D}$ \\
22 & $42.72 \pm 1.40 \mathrm{D}$ & $43.20 \pm 1.94 \mathrm{D}$ \\
23 & $42.59 \pm 0.66 \mathrm{D}$ & $44.38 \pm 1.24 \mathrm{D}$ \\
\hline
\end{tabular}

$\mathrm{CP}$, corneal power; $\mathrm{CCP}$, central corneal power; $\mathrm{D}$, dioptre; s.d., standard deviation. ${ }^{\dagger}$, Independent samples $t$-test.

TABLE 3: Distribution of central corneal power (CCP) in near-emmetropic students in the age range of 18-23 years, (mean 20.5 years).

\begin{tabular}{lcccccc}
\hline Variable & $\begin{array}{c}\mathbf{1 8} \text { years } \\
(\boldsymbol{n}=\mathbf{1 9 )}\end{array}$ & $\begin{array}{c}\mathbf{1 9} \text { years } \\
(\boldsymbol{n}=\mathbf{6 0})\end{array}$ & $\begin{array}{c}\mathbf{2 0} \text { years } \\
(\boldsymbol{n}=\mathbf{4 7 )})\end{array}$ & $\begin{array}{c}\mathbf{2 1} \text { years } \\
(\boldsymbol{n}=\mathbf{3 2})\end{array}$ & $\begin{array}{c}\mathbf{2 2} \text { years } \\
(\boldsymbol{n}=\mathbf{3 6})\end{array}$ & $\begin{array}{c}\mathbf{2 3} \text { years } \\
(\boldsymbol{n}=\mathbf{6})\end{array}$ \\
\hline CCP Mean & $43.75 \mathrm{D} \pm$ & $43.01 \mathrm{D} \pm$ & $43.07 \mathrm{D} \pm$ & $42.90 \mathrm{D} \pm$ & $42.97 \mathrm{D} \pm$ & $43.18 \mathrm{D} \pm$ \\
\pm s.d. & $1.59 \mathrm{D}$ & $1.32 \mathrm{D}$ & $1.68 \mathrm{D}$ & $1.23 \mathrm{D}$ & $1.70 \mathrm{D}$ & $1.92 \mathrm{D}$
\end{tabular}
$\begin{array}{lllllll} \pm \text { s.d. } & 1.59 \mathrm{D} & 1.32 \mathrm{D} & 1.68 \mathrm{D} & 1.23 \mathrm{D} & 1.70 \mathrm{D} & 1.92 \mathrm{D}\end{array}$

, One-way ANOVA test for mean difference of CCP because of age ( $p=0.49)$.

CCP, central corneal power; D, dioptre; s.d., standard deviation; $n$, number; ANOVA, analysis of variance.

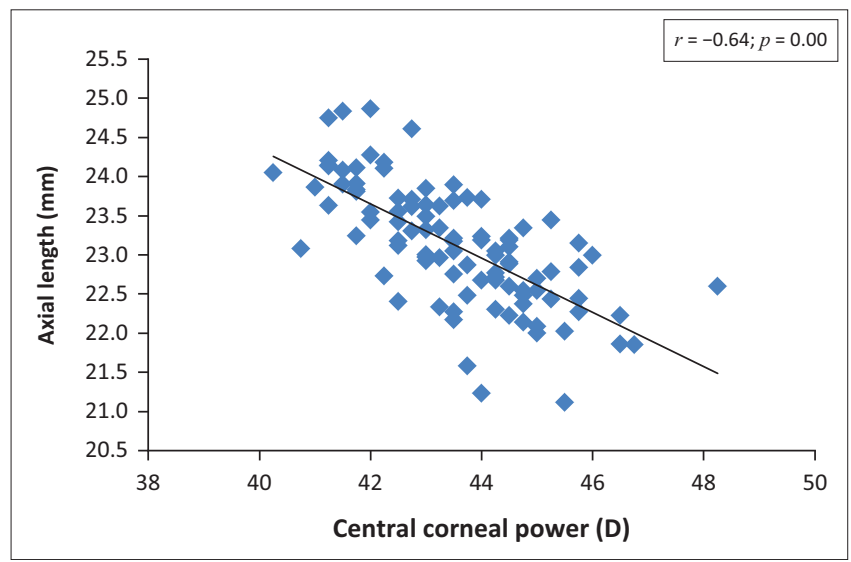

D, dioptre.

FIGURE 2: A significant negative correlation between central corneal power and axial length in male students $(n=97)$.

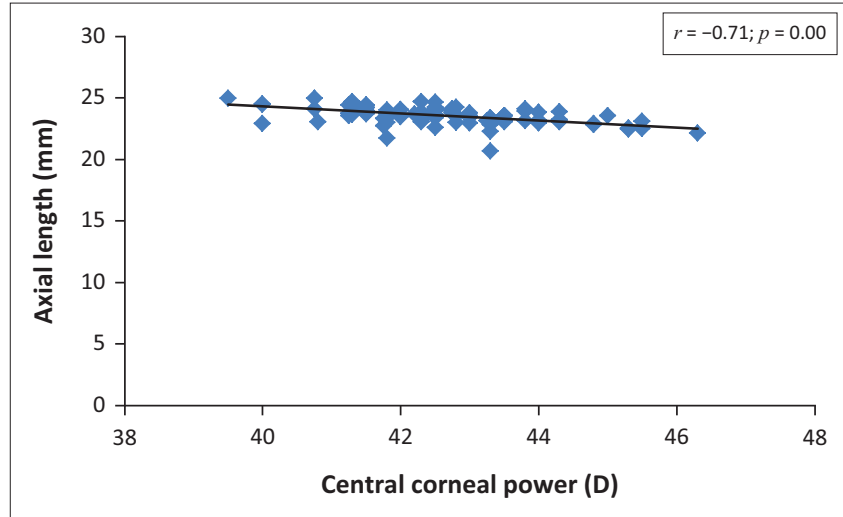

D, dioptre.

FIGURE 3: A significant negative correlation between central corneal power and axial length in female students $(n=103)$.

TABLE 4: Pearson's correlations between central corneal power and some biometric variables in male and female participants.

\begin{tabular}{lcc}
\hline Dependent variables & Males CCP (D) & Females CCP (D) \\
\hline AL $(\mathbf{m m})$ & -0.64 & -0.71 \\
$r$ & 0.00 & 0.00 \\
$p$ & & \\
ACD $(\mathbf{m m})$ & 0.15 & 0.08 \\
$r$ & 0.86 & 0.25 \\
$p$ & & \\
CCT $(\mu \mathrm{m})$ & -0.12 & -0.14 \\
$r$ & 0.16 & 0.86 \\
$p$ & & \\
\hline
\end{tabular}

Note: Significant correlation at $p<0.05$.

Males: $n=97$; Females: $n=103$.

$\mathrm{CCP}$, central corneal power; $\mathrm{AL}$, axial length; $\mathrm{ACD}$, anterior chamber depth; $\mathrm{CCT}$, central corneal thickness; $\mathrm{mm}$, millimetres; $\mathrm{D}$, dioptre; $\mu \mathrm{m}$, micrometre.

the normal CCP of near-emmetropic subjects in Jordan, although with different age group, sample size, methodologies and clinical tests used (Table 5). In male students, CCP was flatter and AL was longer when compared with female Palestinian students. The reason might be because female corneas were significantly thinner than male corneas as observed in Table 5.,18 The results for this study revealed that ACD was $3.59 \mathrm{~mm} \pm$ $0.26 \mathrm{~mm}$ in male and $3.35 \mathrm{~mm} \pm 0.25 \mathrm{~mm}$ in female nearemmetropic subjects. This is consistent with a previous study from Denmark. ${ }^{19}$ Our mean CCT of $549 \mu \mathrm{m} \pm 33 \mu \mathrm{m}$ in male and $543 \mu \mathrm{m} \pm 35 \mu \mathrm{m}$ in female students are slightly lower than previous findings in Nigeria. ${ }^{20}$ This might be because of variations in demographics, race, lifestyles and diagnostic criteria used.

In this study, it was found that our CCP results was normally distributed (see Figure 1), which had been previously reported..$^{20,21}$ In the current study, a significant correlation was observed between CCP and AL in nearemmetropic subjects (see Table 4), and this is in agreement with previous reports. ${ }^{17,18}$ Lira et al. ${ }^{9}$ also demonstrated that steeper corneas tended to have shorter AL. In this study, no correlation was found between CCP and ACD in near-emmetropic eyes of the students. In contrast, a previous report from Taiwan found a significant relationship between $\mathrm{CCP}$ and ACD. ${ }^{18}$ Asian eyes tend to 
TABLE 5: Summary of reports presenting the correlation between central corneal power and a number of variables, which include axial length, anterior chamber depth, central corneal thickness, gender and age.

\begin{tabular}{|c|c|c|c|c|c|c|c|c|c|c|c|c|c|c|}
\hline Authors & Country/area & Gender & $\begin{array}{c}\text { Mean } \\
\text { (years) }\end{array}$ & $\begin{array}{c}\text { Mean range } \\
\text { age (years) }\end{array}$ & $\begin{array}{l}\text { Number of } \\
\text { subjects }\end{array}$ & CCP (D) & $\mathrm{AL}(\mathrm{mm})$ & $\mathrm{ACD}(\mathrm{mm})$ & ССТ $(\mu \mathrm{m})$ & $\begin{array}{c}\text { CCP vs. } \\
\text { AL }\end{array}$ & $\begin{array}{c}\text { CCP vs. } \\
\text { ACD }\end{array}$ & $\begin{array}{c}\text { CCP vs. } \\
\text { CCT }\end{array}$ & $\begin{array}{l}\text { CCP vs. } \\
\text { gender }\end{array}$ & $\begin{array}{l}\text { CCP vs. } \\
\text { age }\end{array}$ \\
\hline Mallen et $\mathrm{al}^{17}$ & Jordan & $\begin{array}{l}\text { Males } \\
\text { Females }\end{array}$ & $\begin{array}{l}29.28 \\
27.39\end{array}$ & - & 1093 & $\begin{array}{l}43.49 \\
44.00\end{array}$ & $\begin{array}{l}23.33 \\
22.99\end{array}$ & $\begin{array}{l}3.17 \\
3.21\end{array}$ & N/A & S & N/A & N/A & $S$ & N/A \\
\hline Chen et al. ${ }^{18}$ & Taiwan & $\begin{array}{l}\text { Males } \\
\text { Females }\end{array}$ & $\begin{array}{l}61.30 \\
60.50\end{array}$ & - & 500 & $\begin{array}{l}43.50 \\
44.30\end{array}$ & $\begin{array}{l}23.50 \\
23.00\end{array}$ & $\begin{array}{l}3.00 \\
2.90\end{array}$ & $\begin{array}{l}555 \\
553\end{array}$ & S & S & NS & S & N/A \\
\hline Olsen et al. ${ }^{19}$ & Denmark & $\begin{array}{l}\text { Males } \\
\text { Females }\end{array}$ & $\begin{array}{l}67.90 \\
68.10\end{array}$ & - & 723 & $\begin{array}{l}43.41 \\
43.73\end{array}$ & $\begin{array}{l}23.74 \\
23.20\end{array}$ & $\begin{array}{l}3.20 \\
3.08\end{array}$ & N/A & S & $\mathrm{N} / \mathrm{A}$ & N/A & S & N/A \\
\hline Zocher et al. ${ }^{8}$ & Germany & $\begin{array}{l}\text { Males } \\
\text { Females }\end{array}$ & $\begin{array}{l}43.00 \\
44.00\end{array}$ & - & 245 & $\begin{array}{l}42.88 \\
43.46\end{array}$ & $\begin{array}{l}24.20 \\
23.40\end{array}$ & $\begin{array}{l}2.92 \\
2.74\end{array}$ & $\begin{array}{l}559 \\
549\end{array}$ & S & S & N/A & S & S \\
\hline Lira et al. ${ }^{21}$ & Brazil & $\begin{array}{l}\text { Males } \\
\text { Females }\end{array}$ & - & $\begin{array}{l}6-17 \\
6-17\end{array}$ & 1100 & $\begin{array}{l}43.30 \\
43.80\end{array}$ & $\begin{array}{l}16.70 \\
16.30\end{array}$ & $\begin{array}{l}3.17 \\
3.06\end{array}$ & $\begin{array}{l}539 \\
537\end{array}$ & S & S & S & NS & NS \\
\hline $\begin{array}{l}\text { Iyamu and } \\
\text { Osuobeni }{ }^{20}\end{array}$ & Nigeria & $\begin{array}{l}\text { Males } \\
\text { Females }\end{array}$ & - & $\begin{array}{l}48.22 \\
47.15\end{array}$ & 130 & $\begin{array}{l}42.83 \\
43.19\end{array}$ & $\mathrm{~N} / \mathrm{A}$ & N/A & $\begin{array}{l}551 \\
546\end{array}$ & N/A & N/A & S & NS & NS \\
\hline Current study & Palestine & $\begin{array}{l}\text { Males } \\
\text { Females }\end{array}$ & - & $\begin{array}{l}20.17 \\
22.00\end{array}$ & 200 & $\begin{array}{l}43.19 \\
43.85\end{array}$ & $\begin{array}{l}23.54 \\
22.94\end{array}$ & $\begin{array}{l}3.59 \\
3.35\end{array}$ & $\begin{array}{l}549 \\
543\end{array}$ & S & NS & NS & S & NS \\
\hline
\end{tabular}

$\mathrm{CCP}$, central corneal power; $\mathrm{AL}$, axial length; $\mathrm{ACD}$, anterior chamber depth; $\mathrm{CCT}$, central corneal thickness; $\mathrm{S}$, statistically significant association; NS, statistically non-significant association N/A, not applicable.

have tighter eyelids and narrow palpebral apertures that could perhaps explain the different results between this study and the previous clinical study ${ }^{18}$. No significant correlation was observed between CCP and CCT in our study. This result was corroborated by a more recent study from Germany. ${ }^{8}$ In contrast, Shimmyo et al. ${ }^{22}$ reported that CCP was negatively correlated with CCT.

In conclusion, the current study provided information on $\mathrm{CCP}, \mathrm{AL}, \mathrm{ACD}$ and CCT in near-emmetropic young students with good health, who were examined in the Optometry Laboratory of the IUG, Palestine. Scores of CCP were normally distributed. Steeper corneas tended to have shorter AL. Men had flatter corneas and longer AL than female Palestinian adults. In contrast, CCP was not significantly influenced by age, ACD and CCT.

The information on the prevalence of emmetropia and the three types of uncompensated refractive error (URE) ([myopia, hypermetropia and astigmatism] and the three severities of RE [mild, moderate and severe]) were not included in the current study. This is a limitation of this study, which should be addressed in future research. Intraocular pressure was not obtained in this study, and this might also be a possible limitation of the study.

\section{Acknowledgements}

The authors thank the Optometry Department of the Islamic University Gaza.

\section{Competing interests}

The authors declare that they have no financial or personal relationships that may have inappropriately influenced them in writing this article.

\section{Authors' contributions}

This article forms part of a Bachelor (BSc) of Optometry research study (Correlations between central corneal power, axial length, anterior chamber depth and central corneal thickness of near-emmetropic young university students in Palestine) undertaken by M.A. as the supervisor. M.A. assisted with the conceptualisation, writing, revision and supervising of the article. A.A.D. contributed to the conceptualisation and writing of the article. F.Q. assisted with data analysis and writing of the article. H.M. assisted with the project management, sourcing of resources and writing of the article. N.B. contributed towards data analysis, sourcing of resources and supervisor A.A.

\section{Funding information}

This research received no specific grant from any funding agency in the public, commercial or not-for-profit sectors.

\section{Data availability}

Data sharing is not applicable to this article.

\section{Disclaimer}

The views and opinions expressed in this article are those of the authors and do not necessarily reflect the official policy or position of any affiliated agency of the authors.

\section{References}

1. Cowan A. Emmetropia. Am J Ophthalmol. 1951;34(7):1021-1024. https://doi org/10.1016/0002-9394(51)91173-7

2. Atchison DA, Jones $\mathrm{CE}$, Schmid KL, et al. Eye shape in emmetropia and myopia. Invest Ophthalmol Vis Sci. 2004;45:3380-3386. https://doi.org/10.1167/ iovs.04-0292

3. Mashige KP. A review of corneal diameter, curvature and thickness values and influencing factors. Afr Vis Eye Health. 2013;72(4):185-194. https://doi. org/10.4102/aveh.v72i4.58

4. Al Hammami HA, Hashem Ali H. Anterior segment optical biometric parameters and refractive errors in a sample of Iraqi population. Prensa Med Argent. 2020;106(5):283. https://doi.org/10.47275/0032-745X-283

5. Orucoglu F, Akman $\mathrm{M}$, Onal $\mathrm{S}$. Analysis of age, refractive error and gender related changes of the cornea and the anterior segment of the eye with Scheimpflug imaging. Cont Lens Anterior Eye. 2015;38(5):345-350. https://doi.org/10.1016/ j.clae.2015.03.009

6. Parrey MUR, Elmorsy E. Prevalence and pattern of refractive errors among Saudi adults. Pak J Med Sci. 2019;35(2):394-398. https://doi.org/10.12669/pjms. 35.2.648

7. Onua AA, Pedro-Egbe CN, Babatunde S. Prevalence of refractive error in a rural Ogoni community in Southern Nigeria. Niger J Ophthalmol. 2012;20(1):30-32. 
8. Zocher MT. Biometry and visual function of a healthy cohort in Leipzig, Germany. BMC Ophthalmol. 2016;16:79. https://doi.org/10.1186/s12886-016-0232-2

9. Lira RPC, Arieta CEL, Passos THM, et al. Distribution of ocular component measures and refraction in Brazilian school children. Ophthalmic Epidemiol. 2017;24(1):29-35. https://doi.org/10.1080/09286586.2016.1254249

10. Iqbal F, Khalil I, Zahid M. Prevalence of refractive errors in school going children in district Faisalabad, Pakistan. Adv Ophthalmol Vis Syst. 2020;10(1):4-6. https://doi.org/10.15406/aovs.2020.10.00372

11. Ruskell GL, Bergmanson JPG. Anatomy and physiology of the cornea and related structures. In: Phillip AJ, Speedwell L, editors. Contact lenses. 5th ed. Oxford: Butterworth-Heinemann, 2006; p. 33-64. https://doi.org/10.1016/B978-0-70207168-3.00003-9

12. Benes $P$, Synek $S$, Petrová $S$. Corneal shape and eccentricity in population. Coll Antropol. 2013;37(Suppl 1):117-120.

13. Jivrajka R, Shammas MC, Boenzi T, Swearingen $M$, Shammas HJ. Variability of axial length, anterior chamber depth, and lens thickness in the cataractous eye J Cataract Refract Surg. 2008;34(2):289-294. https://doi.org/10.1016/j. jcrs.2007.10.015

14. Doughty MJ, Pachymetry S. Part 1: Defining normal corneal thickness and normal IOP measures. Optician. 2005;230:27-31.

15. Ashwin PT, Shah S, Pushpoth S, Wehbeh L, llango B. The relationship of central corneal thickness (CCT) to thinnest central cornea (TCC) in healthy adults. Contact Lens Anterior Eye. 2009;32(2):64-67. https://doi.org/10.1016/j.clae.2008.07.006
16. Sullivan KM. Open source statistics for public health [homepage on the Internet]. [cited 2020 Feb 3]. Available from: http://www.openepi.com/SampleSize/ SSPropor.htm

17. Mallen EA, Gammoh Y, Al Bdour M, Sayegh FN. Refractive error and ocular biometry in Jordanian adults. Ophthalmic Physiol Opt. 2005;25(4):302-309. https://doi.org/10.1111/j.1475-1313.2005.00306.x

18. Chen MJ, Liu YT, Tsai CC, Chen YC, Chou CK, Lee SM. Relationship between central corneal thickness, refractive error, corneal curvature, anterior chamber depth and axial length. J Chin Med Assoc. 2009;72(3):133-137. https://doi.org/10.1016/ S1726-4901(09)70038-3

19. Olsen T, Arnarsson A, Sasaki H, Sasaki K, Jonasson F. On the ocular refractive components: The Reykjavik Eye Study. Acta Ophthalmol Scand. 2007;85(4): 361-366. https://doi.org/10.1111/j.1600-0420.2006.00847.x

20. Iyamu E, Osuobeni E. Age, gender, corneal diameter, corneal curvature and central corneal thickness in Nigerians with normal intraocular pressure. J Optom. 2012;5(2):87-97. https://doi.org/10.1016/j.optom.2012.02.001

21. Heydarian $\mathrm{S}$, Hashemi H, Shokrollahzadeh F, et al. The normal distribution of corneal eccentricity and its determinants in two rural areas of north and south of Iran.J Cur Ophthalmol. 2018;30(2):147-151. https://doi.org/10.1016/j.joco.2017.11.006

22. Shimmyo M, Ross AJ, Moy A, Mostafavi R. Intraocular pressure, Goldmann applanation tension, corneal thickness, and corneal curvature in Caucasians, Asians, Hispanics, and African Americans. Am J Ophthalmol. 2003:136(4):603-613. https://doi.org/10.1016/S0002-9394(03)00424-0 